\title{
Analisis Sport Tourism Pantai Tirta Samudera di Kabupaten Jepara
}

\author{
Muhamad Asnan Maulana', Tubagus Herlambang ${ }^{2}$, Yulia Ratimiasih ${ }^{3}$ \\ Universitas PGRI Semarang. Jln Gajah Raya No 40. Semarang. 50166 \\ muhammadasnanmaulana@gmail.com
}

\begin{abstract}
This research is motivated by the development of the sports sector which is growing rapidly, one of the things that needs to be developed is the type of natural tourism such as on the beach, namely sports tourism activities, including diving, surfing, rolling donuts, namely sitting on a buoy. which looks like a donut, Banana Boat using a banana-shaped rubber boat, and Jet ski. This study uses a qualitative research method in the form of spoken or written words that are observed by researchers, and objects that are observed in detail so that the implied meaning in the document or object can be captured. With the determination of the sample data sources are selected purposively and are snowball sampling, namely the source of information data from the Tourism Office, the Head of the Management of Sport Tourism rides and tourists visiting the Sport Tourism rides. The research location is at Tirta Samudera Beach, the focus of this research is to find out how to analyze the Sport Tourism of Tirta Samudera Beach in Jepara Regency. The data collection techniques and instruments used in this study are using observation, interviews and documentation. The results of this study indicate that the first from the Tourism Office revealed a strategy or effort from the Tourism Office in introducing or promoting the Tirta Samudera Beach Sport Tourism vehicle in Jepara Regency, namely through a website or brochure. The second head of the manager of the Sport Tourism vehicle revealed that in 2020 the rides that have been developing so far are Banana Boat and adding types of Rolling Donuts, Jet Ski, and Kano rides while in the planning stage, namely Flaying Fish and Pareseling which have the same thing being pulled into the air using a Jet Ski. The third is that respondents from tourists enjoying various rides such as Jet Ski, Banana Boat, and Canoe feel their own satisfaction because of their need to exercise. The conclusion is that the Tirta Samudera Beach Sport Tourism rides in Jepara Regency include Banana Boat, Rolling Donuts, Canoe and Jet Ski and from the tourists who enjoy the Sport Tourism rides can feel satisfaction because their need to exercise there are suggestions, namely from the Tourism Office and the Management the Tirta Samudera Beach Sport Tourism vehicle needs to further improve the promotion system or the introduction of Sport Tourism rides through social media or print media so that it can be known by the public who wants to visit.
\end{abstract}

Keywords: Sport Tourism, Tirta Samudera Beach, Sport

\begin{abstract}
Abstrak
Penelitian ini di latar belakangi oleh perkembangan sektor olahraga yang berkembang pesat, salah satu hal yang perlu dikembangkan yaitu adalah jenis wisata alam seperti di pantai yaitu kegiatan Sport Tourism antara lain menyelam (diving), berselancar (surfing), Rolling Donuts yaitu duduk di sebuah pelampung yang bentuknya seperti kue donat, Banana Boat dengan menggunakan perahu karet berbentuk pisang, dan Jet ski. Penelitian ini menggunakan metode penelitian kualitatif yang berupa kata-kata lisan atau tertulis yang dicermati oleh peneliti, dan benda-benda yang diamati sampai detailnya agar dapat ditangkap makna yang tersirat dalam dokuman atau bendanya. Dengan penetapan sampel sumber data dipilih secara purposive dan bersifat snowball sampling yaitu sumber data informasi dari Dinas Pariwisata, Kepala Pengelola wahana Sport Tourism dan para wisatawan yang mengunjungi wahana Sport Tourism. Lokasi penelitian di Pantai Tirta Samudera, fokus penelitian ini adalah untuk mengetahui bagaimana analisis Sport Tourism Pantai Tirta Samudera di Kabupaten Jepara Adapun teknik dan instrumen pengumpulan data yang digunakan dalam penelitian ini adalah menggunakan observasi, wawancara dan dokumentasi. Hasil penelitian ini menunjukan bahwa yang pertama dari Dinas Pariwisata mengungkapkan adanya strategi atau upaya dari pihak Dinas Pariwisata dalam mengenalkan atau mempromosikan wahana Sport Tourism Pantai Tirta Samudera di Kabupaten Jepara yaitu melalui website atau brosur. Yang kedua dari kepala Pengelola wahana Sport Tourism mengungkapkan pada tahun 2020 wahana yang sampai saat ini berkembang yaitu Banana Boat dan menambahi jenis wahana Rolling Donuts, Jet Ski, dan Kano sedangkan dalam tahap perencanaan yaitu Flaying Fish dan Pareseling yang memiliki persamaan ditarik ke udara menggunakan Jet Ski. Yang ketiga yaitu responden dari wisatawan menikmati berbagai wahana seperti Jet Ski, Banana Boat, dan Kano merasakan kepuasan tersendiri karena kebutuhan mereka untuk berolahraga.

Simpulan yaitu wahana Sport Tourism Pantai Tirta Samudera di Kabupaten Jepara antara lain Banana Boat, Rolling Donuts, Kano dan Jet Ski dan dari para wisatawan yang menikmati wahana Sport Tourism dapat
\end{abstract}


merasakan kepuasan karena kebutuhan mereka untuk berolahraga terdapat saran yaitu dari pihak Dinas Pariwisata maupun pihak Pengelola wahana Sport Tourism Pantai Tirta Samudera perlu meningkatkan lagi sistem promosi atau pengenalan wahana Sport Tourism melalui media sosial atau media cetak agar dapat diketahui oleh masyarakat yang ingin berkunjung.

Kata Kunci: Sport Tourism, Pantai Tirta Samudera, Sport

\section{PENDAHULUAN}

Olahraga dan pariwisata adalah gabungan aktivitas yang sangat menguntungkan jika digabungkan, banyak hal positif yang bisa didapatkan dari kegiatan olahraga dan pariwisata salah satunya yaitu menjadikan olahraga sebagai tujuan utama untuk berwisata.

Kondisi Fisik Pantai Bandengan untuk para wisatawan yang cocok dalam kegiatan olahraga perairan, yaitu Banana Boat, Rolling Donuts, Kano dan Jet Ski yang juga berpotensi untuk lebih dikembangkan lagi agar lebih dikenal di masyarakat dalam maupun luar kota bahkan mancanegara.

Agus Indarjo (2013) dalam jurnal penelitiannya yang berjudul kajian kesesuaian dan daya dukung wilayah pesisir Pantai Bandengan Jepara, sebagai upaya optimalisasi pengembangan kegiatan Wisata Bahari. Didalam penelitiannya membahas Pantai Bandengan merupakan pantai yang cukup terkenal dan menjadi andalan Kabupaten Jepara sehingga menjadi daerah tujuan wisata yang cukup populer, tidak hanya bagi masyarakat Jepara, tetapi juga sebagian besar penduduk Jawa Tengah. Hasil Penelitian menunjukkan bahwa Pantai Bandengan Kabupaten Jepara berpotensi untuk dikembangkan sebagai lokasi kegiatan wisata olahraga perairan dan kegiatan wisata yang dapat dikembangkan antara lain Flying Fish dan Rolling Donuts guna melengkapi kegiatan wisata yang telah ada terlebih dahulu yaitu Jet Ski dan Banana Boat.

Berdasarkan rumusan masalah di atas, maka penelitian ini dapat bertujuan:

1. Untuk menganalisis bagaimana Sport Tourism Pantai Tirta Samudera di Kabupaten Jepara terhadap minat wisatawan atau pengunjung dalam maupun luar kota.

2. Untuk mendiskripsikan hasil analisis Sport Tourism Pantai Tirta Samudera di Kabupaten Jepara

\section{METODE}

Jenis Penelitian

Penelitian ini menggunakan jenis penelitian deskriptif (Descriptive Research) adalah penelitian yang bertujuan membuat deskripsi atas suatu fenomena sosial/alam secara sistematis, faktual, dan akurat. Metode kualitatif adalah tampilan yang berupa kata-kata lisan atau tertulis yang dicermati oleh peneliti, dan benda-benda yang diamati sampai detailnya agar dapat ditangkap makna yang tersirat dalam dokuman atau bendanya. 


\section{Subjek Penelitian}

Subjek penelitian berupa informasi yang dijadikan fokus dalam penelitian ini berupa informasi yang diperoleh dari Dinas Pariwisata Kabupaten Jepara, Pengelola Sport Tourism, beserta wisatawan yang menikmati Sport Tourism Pantai Tirta Samudera di Kabupaten Jepara.

\section{Instrumen Pengumpulan Data}

Adapun teknik dan instrumen pengumpulan data yang digunakan dalam penelitian ini yaitu observasi, wawancara dan dokumentasi.

\section{Analisis Data}

Selanjutnya pada analisis data interaktif dapat di ilustrasikan pada gambar sebagai berikut:

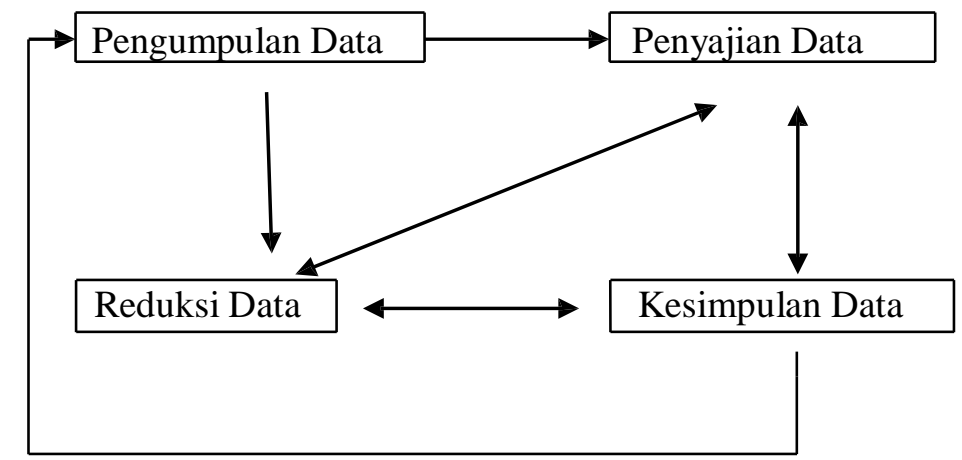

Gambar 1. Model Analisis Data Interaktif

Sumber : Miles dan Huberman dalam Sugiyono (2014: 338)

Teknik analisis data dalam melakukan penelitian ini adalah menggunakan uraian kata-kata yang menggambarkan analisis Sport Tourism Pantai Tirta Samudera di Kabupaten Jepara Kemudian data tersebut dapat disajikan berupa laporan yang dapat didata, direduksi, atau dikoreksi dan disajikan, yang pada tahap akhirnya dapat di tarik kesimpulan.

\section{HASIL DAN PEMBAHASAN}

Potensi atau jenis wahana Sport Tourism atau pariwisata olahraga yang berada di Pantai Tirta Samudera di Kabupaten Jepara. 
Tabel 1. Daftar Potensi Sport Tourism Pantai Tirta Samudera di Kabupaten Jepara

\begin{tabular}{c|l|l|l}
\hline NO & \multicolumn{1}{|c|}{ NAMA } & \multicolumn{1}{|c}{ FASILITAS } & \multicolumn{1}{|c}{ HARGA } \\
\hline 1. & Banana Boat & $\begin{array}{l}\text {-Maksimal empat orang } \\
\text {-2 (dua) kali putaran }\end{array}$ & $\begin{array}{l}\text { Rp.50.000/oran } \\
\text { g }\end{array}$ \\
\hline 2. & Rolling Donuts & $\begin{array}{l}\text {-Maksimal lima orang } \\
\text {-2 (dua) kali putaran }\end{array}$ & $\begin{array}{l}\text { Rp.50.000/oran } \\
\text { g }\end{array}$ \\
\hline 3. & Jet Ski & $\begin{array}{l}\text {-Maksimal dua orang } \\
\text {-15 menit }\end{array}$ & $\begin{array}{l}\text { Rp.190.000/kap } \\
\text { al }\end{array}$ \\
\hline 4. & Kano & $\begin{array}{l}\text {-Maksimal tiga orang } \\
\text {-Tanpa batas waktu } \\
\text { (selama tidak ada yang }\end{array}$ & $\mathbf{R p . 2 0 . 0 0 0 / k a p a}$ \\
\hline
\end{tabular}

Sumber: Kepala Pengelola Sport Tourism Pantai Tirta Samudera

Selanjutnya terdapat gambar data diagram batang mengenai jumlah kunjungan wisatawan Sport Tourism pada tahun 2019 di bawah ini.

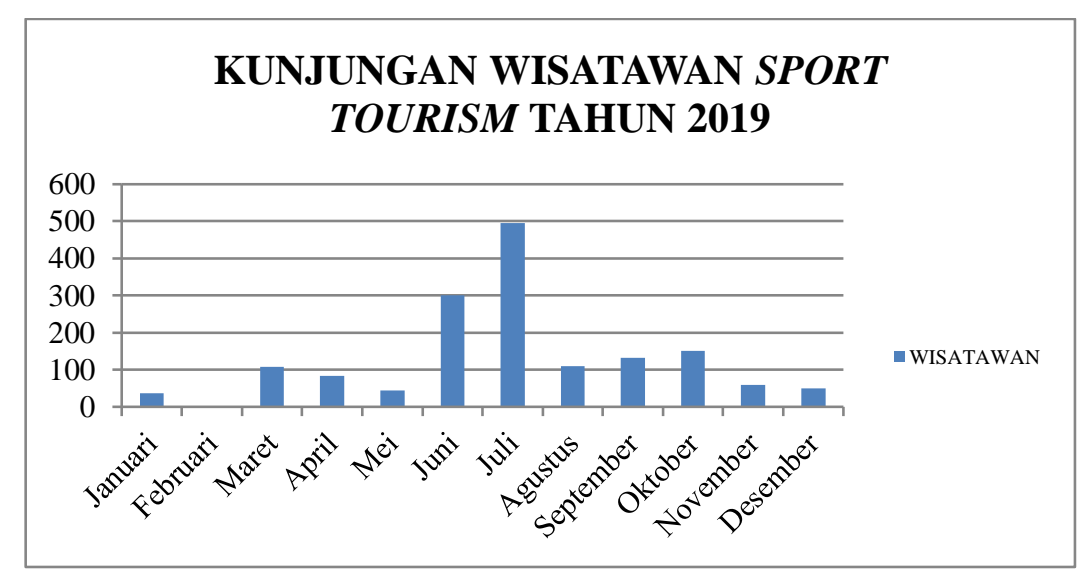

Gambar 2. Diagram Batang Jumlah Wisatawan Sport Tourism Tahun 2019

Sumber: Kepala Pengelola Sport Tourism Pantai Tirta Samudera

Berdasarkan data diagram batang diatas yang diperoleh dari pihak Pengelola Sport Tourism Pantai Tirta Samudera pada tahun 2019 jumlah kunjungan wisatawan Sport Tourism sebanyak 1.569 wisatawan yang berkunjung. Dari jumlah pengunjung atau wisatawan yang telah tercatat dalam data pembukuan Pengelola Sport Tourism jumlah pengunjung yang tertinggi yaitu di bulan Juli mencapai 495 orang atau wisatawan yang berkunjung dan dalam pembukuan tersebut jumlah pengunjung paling sedikit atau bahkan sepi yaitu bulan Februari dikarenakan di bulan tersebut mengalami musim hujan.

Adapun untuk data jumlah kunjungan wisatawan Sport Tourism pada tahun 2020 menurun drastis dikarenakan pada triwulan pertama yaitu bulan Januari sampai Maret tidak beroperasi karena di bulan-bulan tersebut mengalami musim hujan yang tinggi dan selanjutnya untuk bulan Maret sampai Agustus baik wahana maupun obyek wisata Pantai Tirta Samudera tutup sementara dikarenakan adanya 
pandemi Covid-19 demi untuk keselamatan dan kesehatan para wisatawan. Pada bulan September dapat beroperasi kembali atau wahana Sport Tourism aktif kembali sesuai protokol atau anjuran kesehatan dari pemerintah dan untuk pendapatan jumlah kunjungan wisatawan di bulan tersebut mencapai 64 orang atau wisatawan yang berkunjung di wahana Sport Tourism.

Penelitian dilaksanakan berdasarkan data yang diperoleh peneliti dari beberapa subjek atau responden terkait dengan Sport Tourism Pantai Tirta Samudera diantaranya data dari Dinas Pariwisata Kabupaten Jepara, Kepala Pengelola Sport Tourism dan wisatawan yang berkunjung menikmati Sport Tourism Pantai Tirta Samudera di Kabupaten Jepara.

\section{Data Dinas Pariwisata Kabupaten Jepara}

Dari ulasan wawancara bersama Bapak Lukman Aditya sebagai pihak dari Dinas Pariwisata, peneliti dapat menyimpulkan bahwa ada peran serta strategi atau upaya dari pihak Dinas Pariwisata dalam mengenalkan atau mempromosikan wahana Sport Tourism Pantai Tirta Samudera di Kabupaten Jepara yaitu melalui website atau brosur dan tentunya dalam upaya tersebut dari pihak Dinas Pariwisata saling berkomunikasi atau berkoordinasi dengan pihak Pengelola supaya dalam mengenalkan wahana Sport Tourism tersebut dapat meningkatkan jumlah wisatawan yang berkunjung dan dalam hal ini peneliti dapat menganalisis bahwasanya terdapat komunikasi atau koordinasi antara pihak Dinas Parisiwata dan pihak Pengelola Sport Tourism terkait pengenalan wahana Sport Tourism serta dalam pengenalan tersebut memanfaatkan website serta media cetak lainnya seperti brosur.

2. Data Kepala Pengelola Sport Tourism Pantai Tirta Samudera di Kabupaten Jepara

Berdasarkan ulasan hasil wawancara dengan Kepala Pengelola wahana Sport Tourism peneliti dapat menyimpulkan bahwasanya di tempat Sport Tourism terdapat wahana yang sangat berpotensi untuk dikunjungi wisatawan yaitu Banana Boat dan Rolling Donuts yang biayanya sama-sama Rp.50.000 perorang dan juga terdapat wahana Sport Tourism dalam tahap perencanaan yaitu Flaying Fish dan Paraseling yang memiliki persamaan ditarik keudara oleh kendaraan Jet Ski, sedangkan wahana Sport Tourism yang belum dapat dikembangkan yaitu Snokling karena faktor keberadaannya dan keadaan view atau keindahan kedalaman Pantai Tirta Samudera yang kurang mendukung karena jenis pantai yang landai sehingga kurang menguntungkan untuk dikelola.

Sementara itu, dengan adanya wahana Sport Tourism bisa untuk mencapai tujuan kemaslahatan atau manfaat bagi masyarakat berupa mata pencaharian khususnya untuk Pengelola dan umumnya juga untuk dijadikan peluang kerja masyarakat Desa Bandengan dan masyarakat luar juga dan dari hasil penangkapan analisis yang didapat oleh peneliti dari wawancara tersebut yaitu sudah ada wahana yang sampai saat ini berjalan atau beroperasional dan ada juga rencana pembangunan jenis wahana 
lainnya yang pastinya dengan modal banyak selain rencana tersebut ternyata juga ada jenis wahana Snokling yang kurang berjalan akibat view atau keindahan dasaran Pantai yang kurang menarik.

Dari pihak pengelola menambahi jenis wahana seperti Rolling Donuts, Jet Ski dan Kano sedangkan Pigmeble dan Water Fly tidak berkembang karena faktor pembiayaan operasionalnya mahal serta kurang menjadi daya tarik wisatawan.

Dan menurut analisis peneliti terkait fasilitas terutama sarana dan prasarananya yang berada di Sport Tourism Pantai Tirta Samudera sudah tercukupi ketersediaannya bahkan semakin bertambahnya wisatawan yang berkunjung mampu memberikan tambahan modal untuk Pengelola wahana supaya lebih memperbanyak lagi rencana untuk pembangunan jenis wahana Sport Tourism dengan tujuan supaya lebih banyak lagi wisatawan yang datang dan merasakan kepuasan dalam menikmati wahana Sport Tourism Pantai Tirta Samudera.

3. Data Wisatawan Sport Tourism Pantai Tirta Samudera di Kabupaten Jepara

Dari hasil wawancara diatas bersama para wisatawan dari peneliti dapat menyimpulkan bahwa adanya informasi tentang keberadaan Sport Tourism di Pantai Tirta Samudera biasanya bermula dari orang terdekat yaitu keluarga atau bahkan teman dan tidak sedikit pula dari para wisatawan juga dapat mengetahui informasi adanya wahana Sport Tourism di Pantai Tirta Samudera karena sebagaian para wisatawan bisa menemukan informasi tersebut dengan mengunjungi secara langsung di pantai tersebut.

Dan dari hal ini peneliti dapat menganalisis kurang adanya papan info atau sumber informasi tentang Sport Tourism Pantai tirta Samudera di media sosial dan media cetak atau sumber-sumber informasi yang lain dan untuk tingkat kepuasan dari para subjek wisatawan yang menikmati berbagai wahana seperti Jet Ski, Banana Boat, dan Kano merasakan kepuasan tersendiri karena kebutuhan mereka untuk berolahraga.

\section{KESIMPULAN}

Berdasarkan hasil analisis data, pengujian hasil penelitian, dan pembahasan, dapat diambil kesimpulan, yaitu:

1. Sport Tourism Pantai Tirta Samudera di Kabupaten Jepara merupakan salah satu bentuk beberapa aktivitas yang sangat menguntungkan jika digabungkan, banyak hal positif yang bisa didapatkan dari kegiatan olahraga dan pariwisata salah satunya yaitu menjadikan olahraga sebagai tujuan utama untuk berwisata.

2. Terdapat hasil penelitian terdahulu yang mendukung dan relevan dengan penelitian yang dilakukan oleh peneliti yang mendukung tentang analisis Sport Tourism Pantai Tirta Samudera di Kabupaten Jepara. Salah satu hasil penelitian terdahulu yaitu dari Muhammad Syafrizal (2012) dalam penelitiannya yang berjudul analisis program Dinas Kebudayaan, Pariwisata, 
Pemuda dan Olahraga Kabupaten Bengkalis dalam pengembangan objek wisata Pantai Selat Baru di Kecamatan Bantan Kabupaten Bengkalis.

3. Untuk jenis metodelogi penelitian yang dilakukan peneliti dalam menganalisis Sport Tourism Pantai Tirta Samudera di Kabupaten Jepara yaitu menggunakan pendekatan metode penelitian kualitatif yaitu tampilan yang berupa kata-kata lisan atau tertulis yang dicermati oleh peneliti, dan benda-benda yang diamati sampai detailnya agar dapat ditangkap makna yang tersirat dalam dokuman atau bendanya Adapun teknik pengumpulan data yang digunakan dalam penelitian ini adalah observasi, wawancara dan dokumentasi, sedangkan teknik analisis data dari peneliti menggunakan bahan reduksi data, penyajian data dan verifikasi data.

4. Dari hasil penelitian yang dilakukan peneliti berdasarkan rumusan masalah yaitu bagaimanakah analisis Sport Tourism di Pantai Tirta Samudera di Kabupaten Jepara dan bagaimanakah hasil analisis Sport Tourism di Pantai Tirta Samudera di Kabupaten Jepara terhadap responden atau subjek yang diwawancarai terdapat beberapa hasil analisis yang dilakukan oleh peneliti terhadap wahana Sport Tourism Pantai Tirta Samudera. Diantara hasil analisis tersebut yang sudah dilaksanakan oleh peneliti terhadap subjek atau responden yaitu yang pertama dari Dinas Pariwisata mengungkapkan adanya strategi atau upaya dari pihak Dinas Pariwisata dalam mengenalkan atau mempromosikan wahana Sport Tourism Pantai Tirta Samudera di Kabupaten Jepara yaitu melalui website atau brosur dan tentunya dalam upaya tersebut dari pihak Dinas Pariwisata saling berkomunikasi atau berkoordinasi dengan pihak Pengelola supaya dalam mengenalkan wahana Sport Tourism tersebut dapat meningkatkan jumlah wisatawan yang berkunjung dan dalam hal ini peneliti dapat menganalisis bahwasanya terdapat komunikasi atau koordinasi antara pihak Dinas Parisiwata dan pihak Pengelola Sport Tourism terkait pengenalan wahana Sport Tourism serta dalam pengenalan tersebut memanfaatkan website serta media cetak lainnya seperti brosur.

5 .

\section{DAFTAR PUSTAKA}

Agustiana, L. (2013). Analisis Efesiensi Obyek Wisata Di Kabupaten Wonosobo (Skripsi). Semarang: Universitas Diponegoro

Anang, Muhammad, F. (2015) Analisis Faktor-Faktor Yang Mempengaruhi Kunjungan Wisatawan Ke Pantai Kartini Jepara (Skripsi). Semarang: Universitas Diponegoro

Budhiawan, G. \& Agus, I. dkk. (2013). Kajian Kesesuaian dan Daya Dukung Wilayah Pesisir Pantai Bandengan Jepara, sebagai Upaya Optimalisasi Pengembangan Kegiatan Wisata Bahari. Journal Of Marine Research. Vol 2. No. 4. Hal. 74-79 
Chrisman, D, Muktiali, M. (2015). "Dampak keberadaan obyek wisata Pantai Tirta Samudra Kabupaten Jepara terhadap aspek perubahan pemanfaatan lahan, dan sosial-ekonomi masyarakat". Jurnal Teknik PWK. Vol. 4. No. 4. Hal 67

Dwi, Yusniar, R. (2016) Strategi Komunikasi Pemasaran Dinas Pariwisata dan Kebudayaan Kabupaten Jepara Dalam Meningkatkan Jumlah Pengunjung Pantai Tirta Samudera (Skripsi). Semarang: Universitas Diponegoro

Fitriyanto, R.B. (2018). Sensation Seeking Pada Perempuan Pendaki Gunung. Skripsi. Surakarta: Universitas Muhammadiyah Surakarta

Gitapati, D. (2012). Analisis Kunjungan Wisatawan Objek Wisata Nglimut Kecamatan Limbangan Kabupaten Kendal (Skripsi). Semarang: Universitas Diponegoro

Jamalong, A. (2014). "Peningkatan prestasi olahraga nasional secara dini melalui pusat pembinaan dan latihan pelajar (PPLP) dan pusat pembinaan dan latihan mahasiswa (PPLM)". Jurnal Pendidikan Olah Raga. Vol. 3. No. 2. Hal 158

Kasriman. (2017). "Motivasi masyarakat melakukan olahraga rekreasi melalui program care free day di Jakarta". Jurnal Pendidikan Jasmani dan Olahraga. Vol. 2. No. 2. Hal 74

Kholili, I. (2018). Persiapan Fisik Dalam Pendakian Gunung Sindoro (Studi Kasus Pada Anggota Unit Kegiatan Mahasiswa (UKM) Pexinta Alam "Mahapala" Universitas Negeri Semarang Tahun 2017/2018) (Skripsi). Semarang: Universitas Wahid Hasyim.

Kusuma, Dewi. S. (2011) Pengembangan Pariwisata Objek Wisata Pantai Sigandu Kabupaten Batang (Skripsi). Semarang: Universitas Diponegoro

Lauh, A. (2014). "Dimensi olahraga pendidikan dalam pelaksanaan penjasorkes di sekolahan". Jurnal Pendidikan Olah Raga. Vol. 3. No. 1. Hal 84

Mardiatno, D. (2014). Potensi Sumberdaya Pesisir Kabupaten Jepara. Yogyakarta: Gadjah Mada University Press

Moleong, Lexy J. (2010). Metodologi Penelitian Kualitatif. Bandung : Remaja Rosdakarya.

Mujiati, H. (2014). "Analisis dan perancangan sistem informasi stok obat pada apotek arjowinangun". Speed Journal - Sentra Penelitian Engineering dan Edukasi. Vol. 11. No. 2. Hal. 24

Pangestu, H \& Haki, H. (2013). "Analisis angkutan sedimen total pada sungai dawas Kabupaten Musi Banyuasin”. Jurnal Teknik Sipil dan Lingkungan. Vol. 1. No. 1. Hal. 103

Prasetio, Y. (2018). Karakteristik Morfologi Pantai Dan Proses Abrasi Di Pesisir Pasaman Barat. Skripsi. Sumatera Barat: Sekolah Tinggi Keguruan Dan Ilmu Pendidikan (STKIP) PGRI Sumatera Barat.

Rachmiana, Intan, S (2016). Analisis Tingkat Kesulitan Mahasiswa Dalam Melaksanakan PPL (Skripsi). Bandung: Universitas Pasundan

Sahab, M.A. (2017). Pergerakan Gunung DalamAl-Quran (Telaah Penafsiran Surat An-Naml Ayat 88). Skripsi. Surabaya: Universitas Islam Negeri (Uin) Sunan Ampel Surabaya

Soedarso \& Nurif, M. dkk. (2014) "Potensi dan kendala pengembangan pariwisata berbasis kekayaan alam dengan pendekatan marketing places (studi kasus pengembangan pariwisata di Kabupaten Bojonegoro)". Jurnal Sosial Humaniora. Vol. 7. No. 2. Hal 138 
Sugiyono (2014). Memahami Penelitian Kualitatif. Bandung: Alfabeta.

Sugiyono (2016). Metode Penelitian Pendidikan. Bandung: Alfabeta.

Suratmin. (2018). Pengantar Olahraga Rekreasi dan Olahraga Pariwisata. Depok: Rajawali Pers

Sendanita, Y. (2017) Keanekaragaman Dan Kelimpahan Coleoptera Di Pantai Sendangkerta Cipatujah Kabupaten Tasikmalaya (Skripsi). Bandung: Universitas Pasundan

Syafrizal (2012). Analisis Program Dinas Kebudayaan, Pariwisata, Pemuda, dan Olahraga Kabupaten Bengkalis Dalam Pengembangan Objek Wisata Pantai Selat Baru Di Kecamatan Bantan Kabupaten Bengkalis. Skripsi. Riau: Universitas Islam Negeri Sultan Syarif Kasim 